\title{
A CLINICAL STUDY OF ABDOMINAL WOUND DEHISCENCE INCLUDING ITS CAUSES AND MANAGEMENT
}

\author{
Arpan Choudhury1, Ranjit Kumar Deka², Bijit Gogoi ${ }^{3}$, Nitish Kumar4 \\ 1 Postgraduate Student, Department of Surgery, Gauhati Medical College. Assam Medical Council. \\ 2 Professor, Department of Surgery, Gauhati Medical College, Assam Medical Council. \\ 3 Assistant Professor, Department of Surgery, Gauhati Medical College, Assam Medical Council. \\ 4 Postgraduate Student, Department of Surgery, Gauhati Medical College, Bihar Medical Council.
}

\section{ABSTRACT}

\section{BACKGROUND}

Abdominal wound dehiscence is described as partial or complete disruption of an abdominal wound closure with or without protrusion and evisceration of abdominal contents. It is of great concern because there is a risk of evisceration, the need for immediate intervention, and the possibility of repeat dehiscence, surgical wound infection, and incisional hernia formation.

Aims and Objectives- To identify significant risk factors in patients developing abdominal wound dehiscence and to study its incidence in elective and emergency operations, to study the type of incision leading to wound dehiscence and to effectively manage cases and identify steps to minimise the incidence of wound dehiscence/burst abdomen.

\section{MATERIALS AND METHODS}

All the cases that clinically presented as abdominal wound dehiscence after operative procedure, and all patients with wound dehiscence who are referred from other hospitals to Gauhati Medical College \& Hospital during the period of July 2015 to June 2016 were taken for study. An elaborative study of these cases with regard to mode of presentation, significant risk factors, investigations, time and type of surgery and postoperatively, study of diagnosis and day of diagnosis of wound dehiscence is done.

\section{RESULTS}

The mean age of patients with abdominal wound dehiscence was 45.01 years. Out of 56 patients, $39(69.64 \%)$ were male and 17 $(30.36 \%)$ were female. Overall incidence of abdominal wound dehiscence was $2.57 \%$ with incidence in elective surgeries being $0.86 \%$ and in emergency surgeries being $4.99 \%$. Number of cases that developed abdominal wound dehiscence which were opened through vertical incision were 44 (78.57\%) and transverse/oblique incisions were 12 (21.43\%). 43 cases had hypoalbuminaemia. Deranged renal function test was seen in 11 cases, 22 cases had dyselectrolytaemia while 10 patients had increased blood glucose levels. The clinical comorbidities associated with abdominal wound dehiscence were anaemia, intra-abdominal infection/sepsis, uraemia, diabetes mellitus, hypertension, obesity, jaundice and malignancy. 52 patients (92.86\%) had wound dehiscence between $6^{\text {th }}$ to $10^{\text {th }}$ postoperative day and the mean of days of wound dehiscence was 8.16 days. Out of the 56 cases, 8 cases (14.29\%) had complete wound dehiscence and were managed by tension suturing. 48 cases (85.71\%) had partial wound dehiscence and 41 (73.21\%) of them were managed by secondary suturing while 7 cases $(12.50 \%)$ were managed conservatively. Average duration of hospital stay in patients of abdominal wound dehiscence was 22.33 days.

\section{CONCLUSION}

Patients with risk factors like older age group, male sex, anaemia, malnutrition, obesity, peritonitis require more attention and special care to minimise the risk of occurrence of wound dehiscence. Emergency procedures and vertical incisions are more prone to develop wound dehiscence. Simple investigations like HB, RBS, RFT, LFT, chest x-ray may help to detect predisposing factors. Good and active resuscitation of patients before surgery with emphasis on fluid and electrolytes balance, antibiotic cover, nasogastric tube aspiration, and proper intake and output monitoring, will pay in the end.

\section{KEYWORDS}

Abdominal Wound Dehiscence.

HOW TO CITE THIS ARTICLE: Choudhury A, Deka RK, Gogoi B, et al. A clinical study of abdominal wound dehiscence including its causes and management. J. Evolution Med. Dent. Sci. 2017;6(19):1519-1523, DOI: 10.14260/Jemds/2017/334

\section{BACKGROUND}

Abdominal wound dehiscence is described as partial or complete disruption of an abdominal wound closure with or without protrusion and evisceration of abdominal contents. ${ }^{1}$

Financial or Other, Competing Interest: None.

Submission 02-01-2017, Peer Review 21-02-2017,

Acceptance 27-02-2017, Published 06-03-2017.

Corresponding Author:

Dr. Ranjit Kumar Deka,

\#3, Hill Side, Kushal Konwar Road,

Guwahati-781003, Assam, India.

E-mail: ranjit_deka@yahoo.co.uk

DOI: $10.14260 /$ jemds $/ 2017 / 334$

(c) $\bigcirc$
It is one of the most dreaded complications faced by surgeons worldwide. It is of great concern because there is a risk of evisceration, the need for immediate intervention, and the possibility of repeat dehiscence, surgical wound infection, and incisional hernia formation.

Acute wound failure occurs in approximately $1 \%$ to $3 \%$ of patients who undergo an abdominal operation. Dehiscence most often develops 7 to 10 days postoperatively but may occur any time after surgery, from 1 to more than 20 days.

The incidence of wound dehiscence varies from centre to centre worldwide, with some centres in India recording incidence as high as $10-30 \%{ }^{2}$ This may be due to the fact that many patients in India have a poor nutritional status and the 
presentation of these patients with peritonitis is often delayed in the emergency.

Various risk factors are responsible for wound dehiscence such as emergency surgery, intra-abdominal infection, malnutrition (hypoalbuminaemia, anaemia), advanced age $>65$ years, systemic diseases (uraemia, diabetes mellitus) etc. Good knowledge of these risk factors is mandatory for prophylaxis.

The need for this study is to highlight the risk factors for wound dehiscence, the incidence rate in this hospital and the measures to prevent or reduce the incidence of wound dehiscence and to effectively manage the cases of abdominal wound dehiscence.

\section{Aims and Objectives}

1. To identify significant risk factors in patients developing abdominal wound dehiscence.

2. To study the incidence of wound dehiscence in elective and emergency operation.

3. To study the type of incision leading to wound dehiscence.

4. To effectively manage cases of wound dehiscence and identify steps to minimise the incidence of wound dehiscence/ burst abdomen.

\section{MATERIAL AND METHODS}

\section{Inclusion Criteria}

1. Patients of more than 12 years of age and either sex.

2. Patients presenting with abdominal wound dehiscence after undergoing elective or emergency operation.

3. Patients who are ready for investigations and treatment for their condition.

\section{Exclusion Criteria}

1. Patients of less than 12 years of age.

2. All patients who refuse investigation and treatment.

3. All patients with wound dehiscence on sites other than abdomen.

\section{Method of Collecting Data}

All the 56 cases that clinically presented as abdominal wound dehiscence after operative procedure and all patients with wound dehiscence who are referred from other hospitals to Gauhati Medical College \& Hospital during the period of July 2015 to June 2016 were taken for study. An elaborative study of these cases with regard to date of admission, clinical history regarding the mode of presentation, significant risk factors, investigations, time of surgery and type of surgery and postoperatively, study of diagnosis and day of diagnosis of wound dehiscence is done till the patient is discharged from the hospital.

In history, details regarding presenting complaints, duration, associated diseases, significant risk factors like anaemia, malnutrition, obesity, chronic cough were noted. Details regarding the clinical diagnosis, whether the operation was conducted in emergency or elective and the type of incision were noted. Intraoperative findings were noted and classification of surgical wounds done accordingly. The type of surgical procedure done was also recorded.

The method of abdominal closure in all cases which underwent laparotomy was guided by standard hospital protocols. In all the patients who underwent midline laparotomy, closure was done by a continuous, en masse closure technique using a monofilament, slowly-absorbable suture like polydioxanone (PDS) or polyglyconate (Maxon) while in patients with transverse, oblique or paramedian incisions, layered closure was done using polydioxanone or polyglyconate.

The management of these cases of wound dehiscence was done based on facility available in Gauhati Medical College \& Hospital.

\section{Data Management and Analysis}

All data obtained from medical records were entered into a proforma questionnaire. At analysis, each item in the questionnaire was analysed separately using the tally method. Chi-square test was performed where necessary.

\section{RESULTS}

The mean age of patients with abdominal wound dehiscence was 45.01 years (S.D. $=16.59$ ). Majority of patients belonged to the age group $41-50$ years (15 patients, $26.79 \%$ ) with the youngest being 12 years old and the oldest 90 years old. Out of 56 patients, $39(69.64 \%)$ were male and 17 (30.36\%) were female.

In this study, 45 cases $(80.36 \%)$ were operated as emergency surgery and 11 cases $(19.64 \%)$ were operated as elective surgery.

Overall incidence of abdominal wound dehiscence $=$ $2.57 \%$. Incidence of abdominal wound dehiscence in elective surgeries $=0.86 \%$. Incidence of abdominal wound dehiscence in emergency surgeries $=4.99 \%$ (Table 1 ).

\begin{tabular}{|c|c|c|c|c|}
\hline & $\begin{array}{c}\text { Wound } \\
\text { Dehiscence }\end{array}$ & $\begin{array}{c}\text { No } \\
\text { Wound } \\
\text { Dehiscence }\end{array}$ & Total & $\begin{array}{c}\text { Incidence of } \\
\text { Wound } \\
\text { Dehiscence }\end{array}$ \\
\hline Elective & 11 & 1268 & 1279 & $0.86 \%$ \\
\hline Emergency & 45 & 857 & 902 & $4.99 \%$ \\
\hline Total & $\mathbf{5 6}$ & $\mathbf{2 1 2 5}$ & $\mathbf{2 1 8 1}$ & $\mathbf{2 . 5 7 \%}$ \\
\hline \multicolumn{3}{|c|}{ Table 1. Incidence of Abdominal Wound Dehiscence } \\
in Elective and Emergency Surgeries \\
\hline
\end{tabular}

Chi square test was performed for relationship between urgency of surgery and wound failure. Chi square statistic was 36.0452 and $p$ value was $<0.05$ and it showed that patient undergoing emergency surgery had a greater risk of having wound failure than those undergoing elective surgery and it was statistically significant.

No. of cases that developed abdominal wound dehiscence which were opened through vertical incision were 44 $(78.57 \%)$ and transverse/oblique incisions were 12 (21.43\%).

No. of cases which were opened through midline incision were $37(66.07 \%)$ and paramedian incision were $7(12.5 \%)$. (Tables 2A \& 2B).

\begin{tabular}{|c|c|c|c|c|}
\hline $\begin{array}{c}\text { Incision } \\
\text { Type }\end{array}$ & $\begin{array}{l}\text { No. of } \\
\text { Cases }\end{array}$ & Percentage & & Total \\
\hline Midline & 37 & $66.07 \%$ & \multirow{2}{*}{ Vertical } & \multirow{2}{*}{$\begin{array}{c}44 \\
(78.57 \%\end{array}$} \\
\hline Paramedian & 7 & $12.5 \%$ & & \\
\hline Kocher's & 9 & $16.07 \%$ & \multirow{2}{*}{$\begin{array}{c}\text { Oblique/ } \\
\text { Transverse }\end{array}$} & \multirow{2}{*}{$\begin{array}{c}12 \\
(21.43 \%) \\
\end{array}$} \\
\hline Others & 3 & $5.36 \%$ & & \\
\hline & 56 & $100 \%$ & & 56 \\
\hline $\begin{array}{l}\text { Tab } \\
\text { Del }\end{array}$ & A. Inc & ence of Abdo & minal Wout & \\
\hline
\end{tabular}




\begin{tabular}{|c|c|c|c|c|}
\hline & $\begin{array}{c}\text { Wound } \\
\text { Dehiscence }\end{array}$ & $\begin{array}{c}\text { No Wound } \\
\text { Dehiscence }\end{array}$ & Total & $\begin{array}{c}\text { Incidence } \\
\text { of Wound } \\
\text { Dehiscence }\end{array}$ \\
\hline Vertical & 44 & 735 & 779 & $5.65 \%$ \\
\hline $\begin{array}{c}\text { Transverse/ } \\
\text { Oblique }\end{array}$ & 12 & 1390 & 1402 & $0.85 \%$ \\
\hline Total & $\mathbf{5 6}$ & $\mathbf{2 1 2 5}$ & $\mathbf{2 1 8 1}$ & $\mathbf{2 . 5 7 \%}$ \\
\hline \multicolumn{5}{|c|}{ Table 2B. Incidence of Abdominal Wound } \\
Dehiscence in Relation to type of Incision
\end{tabular}

Chi square test was performed for relationship between type of incision and wound failure. Chi square statistic was 45.9717 and $p$ value was $<0.05$ and it showed that patient undergoing surgery through a vertical incision had a greater risk of having wound failure than those undergoing surgery through transverse/oblique incision. Also, the risk of wound failure is more with midline incision than paramedian incision.

Out of 56 patients of abdominal wound dehiscence, 22 patients had peritonitis due to hollow viscus perforation and 6 patients had intestinal obstruction. 5 patients were operated for appendicular abscess or perforation and 6 patients had blunt trauma abdomen. 9 patients underwent surgery for biliary tract pathology like cholelithiasis, choledocholithiasis and choledochal cyst and there were 3 cases of malignancy. One case developed wound dehiscence following biliary peritonitis due to gallbladder perforation. There was 1 case of ileostomy for closure and 2 cases of obstructed inguinal hernia that required resection \& anastomosis.

There was also 1 case of post-dated pregnancy who underwent LSCS in a peripheral hospital following which she developed wound dehiscence on $11^{\text {th }}$ post-operative day and was referred to the Surgery Dept. of GMCH.

25 cases had undergone perforation closure while 11 cases had resection and anastomosis. Appendicectomy was done in 5 cases. 9 cases underwent cholecystectomy/choledocholithotomy, 1 case of choledochal cyst was treated with hepaticojejunostomy, while another 1 case was subjected to extended cholecystectomy for suspected carcinoma gallbladder. There was 1 case of ileostomy closure, 1 case of transverse loop colostomy for carcinoma rectum and 1 case of splenectomy. 1 patient had undergone LSCS for post-dated pregnancy.

Out of the 56 cases of abdominal wound dehiscence, 37 patients were anaemic while 43 cases had hypoalbuminaemia. Deranged renal function test was seen in 11 cases and 22 out of the 56 cases had dyselectrolytaemia while 10 patients had increased blood glucose levels.

One way Chi-square test was applied to find out the relation between the deranged preoperative investigations and abdominal wound dehiscence and it was found that the relation of abdominal wound dehiscence with low haemoglobin (chi square $=5.786$ and $p$ value $<0.05$ ) and hypoalbuminaemia (chi square $=16.071$ and $p$ value $<0.0001$ ) were statistically significant. (Table 3 ).

\begin{tabular}{|c|c|c|}
\hline $\begin{array}{c}\text { Pre-Operative } \\
\text { Investigation }\end{array}$ & Normal & Deranged \\
\hline Haemoglobin & $19(33.93 \%)$ & $37(66.07 \%)$ \\
\hline Albumin & $13(23.21 \%)$ & $43(76.79 \%)$ \\
\hline Electrolytes & $34(60.71 \%)$ & $22(39.29 \%)$ \\
\hline RFT & $45(80.36 \%)$ & $11(19.64 \%)$ \\
\hline RBS & $46(82.14 \%)$ & $10(17.86 \%)$ \\
\hline \multicolumn{2}{|c|}{ Table 3. Relation of Pre-Operative Investigations } \\
with Abdominal Wound Dehiscence \\
\hline
\end{tabular}

Anaemia was a frequent clinical comorbidity associated with abdominal wound dehiscence in 37 cases (66.07\%), intra-abdominal infection/sepsis was present in 43 cases (76.78\%), uraemia was seen in 11 cases (19.64\%), diabetes mellitus in 10 cases (17.86\%), hypertension in 14 cases (25\%), obesity in 20 cases $(35.71 \%)$, jaundice in 5 cases $(8.93 \%)$, and malignancy in 3 cases $(5.36 \%)$. None of the patients were on steroid therapy, cytotoxic drugs or radiation therapy and none of the patients were retrovirus seropositive.

Majority of the patients had more than one clinical comorbidity associated with their abdominal wound dehiscence.

One way Chi-square test was applied to find out the relation between the clinical comorbidities and abdominal wound dehiscence, and it was found that the relation of abdominal wound dehiscence with anaemia (Chi square = 5.786 and $\mathrm{p}$ value $<0.05$ ) and intra-abdominal infection/sepsis (Chi square $=16.071$ and $\mathrm{p}$ value $<0.0001$ ) were statistically significant. (Table 4).

\begin{tabular}{|c|c|c|}
\hline Comorbidity & Present & Absent \\
\hline Anaemia & $37(66.07 \%)$ & $19(33.93 \%)$ \\
\hline $\begin{array}{l}\text { Intra-abdominal } \\
\text { Infection/Sepsis }\end{array}$ & $43(76.78 \%)$ & $13(23.22 \%)$ \\
\hline Uraemia & $11(19.64 \%)$ & $45(80.36 \%)$ \\
\hline Diabetes & $10(17.86 \%)$ & $46(82.14 \%)$ \\
\hline Hypertension & $14(25 \%)$ & $42(75 \%)$ \\
\hline Obesity & $20(35.71 \%)$ & $36(64.29 \%)$ \\
\hline Jaundice & $5(8.93 \%)$ & $51(91.07 \%)$ \\
\hline Malignancy & $3(5.36 \%)$ & $53(94.64 \%)$ \\
\hline \multicolumn{2}{|c|}{ Table 4. Clinical Comorbidities } \\
Associated with Wound Dehiscence \\
\hline \multicolumn{2}{|c}{}
\end{tabular}

Abdominal distension was present in majority of the patients - 39 (69.64\%).

Fever was present in 25 patients (44.64\%). 21 patients (37.50\%) complained of cough, while 16 patients $(28.57 \%)$ had vomiting. Most of the patients had more than one presenting complaint associated with their wound dehiscence. 20 cases (35.71\%) were overweight with BMI $>25$ while 36 cases $(64.29 \%)$ had normal BMI $<25$.

52 patients $(92.86 \%)$ had wound dehiscence between $6^{\text {th }}$ to $10^{\text {th }}$ postoperative day. 2 patients $(3.57 \%)$ developed wound dehiscence between $1^{\text {st }}$ and $5^{\text {th }}$ day while another 2 patients $(3.57 \%)$ developed wound dehiscence after $11^{\text {th }}$ day. The minimum day of wound dehiscence was $5^{\text {th }}$ postoperative day while the maximum day was $13^{\text {th }}$ day. The mean of day of wound dehiscence was 8.16 days with S.D. = 1.57 .

Out of the 56 cases of abdominal wound dehiscence, 8 cases (14.29\%) had complete wound dehiscence and were managed by tension suturing. 48 cases $(85.71 \%)$ had partial wound dehiscence and 41 (73.21\%) of them were managed by secondary suturing while 7 cases $(12.50 \%)$ were managed conservatively. (Table 5). Other methods of closure of burst abdomen like Bogota bags and vacuum technique were not employed due to non-availability of these methods of management. 


\begin{tabular}{|c|c|c|c|}
\hline $\begin{array}{c}\text { Type } \\
\text { of Wound } \\
\text { Dehiscence }\end{array}$ & Management & $\begin{array}{l}\text { No. of } \\
\text { Cases }\end{array}$ & Percentage \\
\hline \multirow{2}{*}{ Partial } & Secondary Suturing & 41 & $73.21 \%$ \\
\hline & Conservative & 7 & $12.50 \%$ \\
\hline Complete & Tension Suturing & 8 & $14.29 \%$ \\
\hline \multicolumn{2}{|r|}{ Total } & 56 & $100 \%$ \\
\hline \multicolumn{4}{|c|}{$\begin{array}{l}\text { Table 5. Types of Wound Dehiscence } \\
\text { and their Management }\end{array}$} \\
\hline
\end{tabular}

Average duration of hospital stay in patients of abdominal wound dehiscence was 22.33 days which increases the economic burden on both the patient and the hospital. Range of hospital stay varied from 13-33 days. 28 cases (50\%) had hospital stay between 21-25 days, only 2 cases (3.57\%) had hospital stay between 11-15 days while 1 (1.79\%) patient had to stay for $>31$ days. Average duration of hospital stay in patients of abdominal wound dehiscence managed conservatively was 18.71 days while those managed by secondary suturing and by deep tension suturing were 22.29 days and 25.75 days respectively.

After repair of the wound dehiscence, the re-infection rate was remarkably minimal and no patient developed wound dehiscence again in the ward. Also there was no mortality in any of the cases. Followup in the study group was erratic with some patients lost to followup after discharge. In all the cases that followed up there were no recorded complications of the repaired wounds or those managed conservatively.

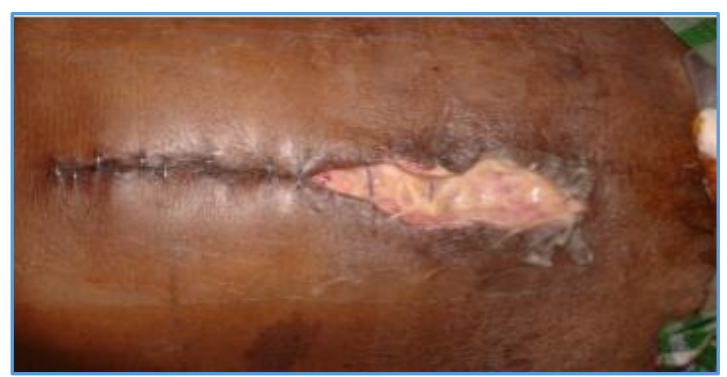

Figure 1. Partial Wound Dehiscence with Slough

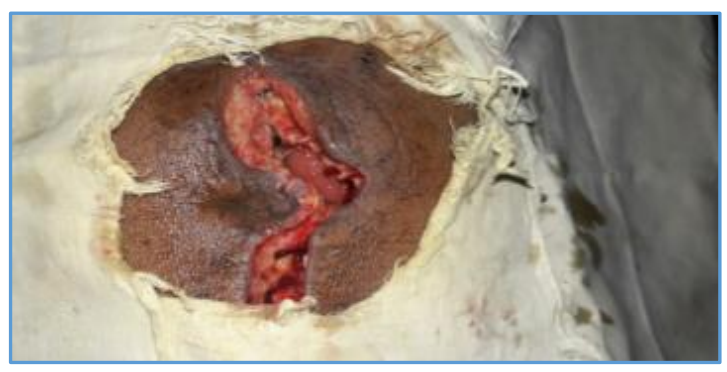

Figure 2. Complete Wound Dehiscence in a Midline Incision

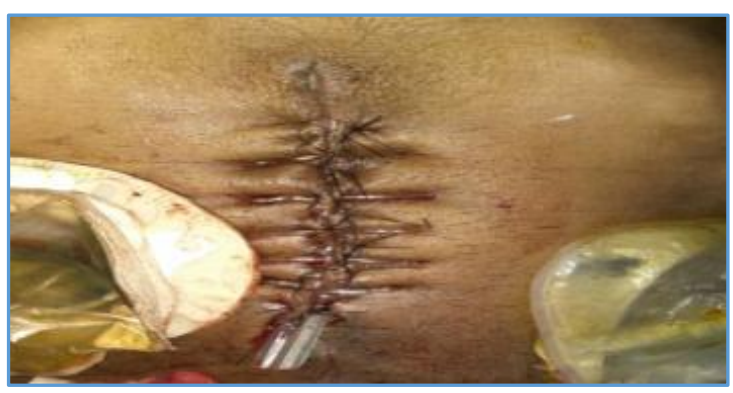

Figure 3. Deep Tension Suturing in Complete Wound Dehiscence

\section{DISCUSSION}

Wound dehiscence is a very serious complication of abdominal surgery, with no single cause being responsible; rather it is a multifactorial problem. ${ }^{3}$

In this clinical study, a total of 56 patients who developed abdominal wound dehiscence after operation in Gauhati Medical College and Hospital were studied.

The overall abdominal wound failure rate was found to be $2.57 \%$. This was in accordance with the rates of $1-3 \%$ found in international literature. Niggebrugge A and Hansen B reported a failure rate of $1 \%(45 / 3768)$ in patients who had undergone midline laparotomy in a 5-year period (1986$1990)^{4}$ while Bucknall TE et al reported failure rate of $1.7 \%$ (19/1129) over a 5-year period (1975-1980). ${ }^{5}$

In the present study, incidence of wound dehiscence in emergency cases was $4.99 \%$ while that in elective cases was $0.86 \%$. Of all the cases that developed wound dehiscence, $19.64 \%$ were elective surgeries and $80.36 \%$ were emergency surgeries. This difference of wound dehiscence rates between elective and emergency laparotomies is statistically significant $(\mathrm{P}<0.05)$.

McGinn reported $6.4 \%$ and $2.6 \%$ rate of wound dehiscence in emergency and elective laparotomy respectively. ${ }^{6}$ In a study by Waqar et al, wound dehiscence rate was observed to be $12 \%$ in emergency (5/62), and $4 \%$ in elective laparotomies $(2 / 55)^{7}$ while Abdul et al found a significantly higher frequency of burst abdomen in emergency laparotomies i.e. $14.89 \%$ as compared to elective laparotomies i.e. $2.7 \%$. Similar observation has been made by Penninckx et al $^{8}$ where wound dehiscence rate was found to be $6.7 \%$ in emergency laparotomy and $1.5 \%$ in elective cases.

The lower incidence of burst abdomen in the elective cases compared to the emergency cases is because in elective cases there is time to correct or control the risk factors such as anaemia, diabetes, malnutrition, hypoproteinaemia, etc. Also there is no abdominal sepsis or increased intraabdominal pressure in the elective cases. ${ }^{9}$ In our setup, the emergency laparotomies are usually performed for acute abdomen cases which have deteriorated due to course of acute illness and by the time they are referred to tertiary care hospitals like GMCH, most of them are already having complications like septicaemia and fluid and electrolytes derangements. Second factor responsible may be the high workload in a busy emergency setup with lack of adequate time for elaborate preparation. Third factor, which can also play a major role in developing wound dehiscence, is lack of experience on part of surgeon. The emergency laparotomies are performed most of the time by surgical residents at odd hours which could lead to suboptimal closure of the abdomen at the end of operation.

In our study, males predominated the picture with the ratio of 2.3: 1 and the mean age of patients was found to be 45.01 years. This was in concordance with other studies by Hampton et.al (1963),10 Waqar et al(2002),7 Spiliotis J. et.al (2007), ${ }^{11}$ Gabrie"lle H. van Ramshorst et al (2010),12 Garg Ramaneesh et al (2014) ${ }^{13}$ and Naga et al (2015).14 This male predominance may be due to the higher incidence of peptic ulcer perforation and intestinal obstruction in male sex.

The mean postoperative day of wound dehiscence was $8^{\text {th }}$ day. In our study, $66 \%$ of patients had anaemia, $25 \%$ hypertension, $19 \%$ uraemia, $35 \%$ obesity, $17 \%$ diabetes while sepsis was a major determinant in $77 \%$ of the cases. 
Also, it was found that $39 \%$ of the patients studied were operated for hollow viscus perforation, $10 \%$ had small bowel obstruction and $5 \%$ had underlying malignancy.

For the patients with bowel perforation which were classified mostly into contaminated surgical wounds, the procedure performed was perforation closure with peritoneal lavage. Patients with appendicular perforation and abscess underwent appendicectomy with peritoneal toilet while most patients diagnosed with intestinal obstruction underwent resection and anastomosis.

In the present study, the no. of cases of wound dehiscence that were opened through vertical incision were $44(78.57 \%)$ and transverse/oblique incisions were 12 (21.43\%). This difference of wound dehiscence rates between vertical and transverse/oblique incisions is statistically significant $(\mathrm{P}<0.05)$. Also, the risk of wound failure is more with midline incision than paramedian incision.

Out of the 56 cases of abdominal wound dehiscence, 8 cases $(14.29 \%)$ of complete dehiscence were managed by tension suturing, 41 cases $(73.21 \%)$ of partial dehiscence were managed by secondary suturing while 7 cases $(12.50 \%)$ of partial dehiscence were managed conservatively. Tension suturing is a simple and effective way of managing burst abdomen which is associated with less morbidity and mortality. The idea of this technique is that by approximating the two recti without strangulating the tissue, the tension over the midline sutures is released and the wound is given a better chance to heal with no tension or cutting through. It was also seen that partial wound dehiscence cases can be effectively managed by secondary suturing or conservatively by allowing the wound to heal by formation of granulation tissue

\section{CONCLUSION}

Abdominal wound dehiscence causes significant morbidity. Patients with risk factors like older age group, male sex, anaemia, malnutrition, obesity, peritonitis require more attention and special care to minimise the risk of occurrence of wound dehiscence. Emergency procedures are more prone for wound dehiscence than elective procedures and vertical incisions are more prone to develop wound dehiscence than transverse/oblique incisions. Also, the risk of wound failure is more with midline incision than paramedian incision. Simple investigations like HB, RBS, RFT, LFT, chest X-ray may help to detect predisposing factors. Wound dehiscence leads to prolonged hospital stay and increased health expenditure which can be prevented by improving the nutritional status of the patient, strict aseptic precautions, avoiding midline incisions, avoiding postoperative cough and vomiting and by proper surgical technique. Good and active resuscitation of patients before surgery with emphasis on fluid and electrolytes balance, antibiotic cover, nasogastric tube aspiration, and proper intake and output monitoring, will pay in the end. Strict post-operative care with stress on prevention of wound infection, chest complications, and ileus can avoid wound dehiscence.

\section{REFERENCES}

[1] Savage A, Lamont M. Wound dehiscence, incisional hernia, and parastomal hernia. In: Morris PJ, Wood WC, (eds). $2^{\text {nd }}$ edn. Oxford text book of surgery. Alison Langton 2000:p 1883.

[2] Dumanian GA, Denham W. Comparison of repair techniques for major incisional hernias. Am J Surg 2003;185(1):61-5.

[3] Lotfy W. Burst abdomen: is it a preventable complication? Egyptian Journal of Surgery 2009;28(3)128-32.

[4] Niggebrugge AH, Hansen BE, Trimbos JB, et al. Mechanical factors influencing the incidence of burst abdomen. European Journal of Surgery 1995;161(9):665-61.

[5] Bucknall TE, Cox PJ, Ellis H. Burst abdomen and incisional hernia: a prospective study of 1129 major laparotomies. $\mathrm{Br}$ Med J (Clin Res $\mathrm{Ed}$ ) 1982;284(6320):931-3.

[6] McGinn FP, Hamilton JC. Ascorbic acid levels in stored blood and in patients undergoing surgery after blood transfusion. Br J Surg 1976;63(7):505-7.

[7] Waqer SH, Malik ZI, Razzaq A, et al. Frequency and risk factors for wound dehiscence/burst abdomen in midline laparotomies. Journal Ayub Med Coll 2005;17(4):70-3.

[8] Penninckx FM, Poelmans SV, Kerremans RP, et al. Abdominal wound dehiscence in gastroenterological surgery. Ann Surg 1979;189(3):345-52.

[9] Sivender A, Ilaiah M, Reddy GS. A clinical study on risk factors causing abdominal wound dehiscence and management. IOSR J Dent Med Sci Ver IV 2015;14(10):18-23.

[10] Hampton JR. The burst abdomen. Br Med J 1963;2(5364):1032-5.

[11] Spiliotis J, Konstantino S, Tsiveriotis, et al. Wound dehiscence: is still a problem in the 21st century: a retrospective study. World Journal of Emergency surgery 2009;4:12.

[12] Ramshorst VGH, Nieuwenhuizen J, Hop WC, et al. Abdominal wound dehiscence in adults: development and validation of a risk model. World J Surg 2010;34(1):20-7.

[13] Ramaneesh G, Sheerin S, Surinder S. A prospective study of predictors for post laparotomy abdominal wound dehiscence. Journal of Clinical and Diagnostic Research 2014;8(1):80-3.

[14] Muneiah NS, Kumar RNM, Sabitha P, et al. Abdominal wound dehiscence- a look into the risk factors. IOSR J Dent Med Sci Ver I 2015;14(10):47-54. 